\title{
Indian Contribution to Obstetrics and Gynecology
}

\author{
Purandare C. N. • Patel Madhuri A. • \\ Balsarkar Geetha
}

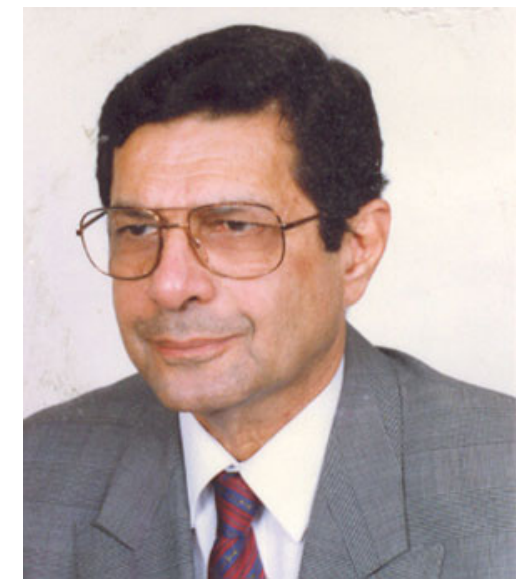

Dr. Rustum P. Soonawala

When he was just a toddler, he would accompany his father to his clinic and see patients paying him four annas. In his younger years, the dining table conversation would revolve around anesthesia, surgical procedures, and X-ray

Purandare C. N. ( $₫)$, Ex Professor

Grant Medical College, Mumbai, India

e-mail: jlnobgynspringer@gmail.com

Patel M. A., Professor and HOD

ESI-PGIMSR, MGM Hospital, Parel, Mumbai, India

Balsarkar G., Professor

Nowrosjee Wadia Maternity Hospital and Seth G.S. Medical College, Parel, Mumbai, India reports. It was no surprise that when the little boy grew up, he was applauded as the medical world's golden boy, Dr. Rustum P. Soonawala.

Dr. Rustom Phiroze Soonawala, MD, FRCS, FRCOG, FICOG, is a very dynamic senior obstetrics and gynecology consultant attached to Breach Candy Hospital \& Research Centre, Mumbai, and Jaslok Hospital \& Research Centre, Mumbai.

He is Professor Emeritus of Seth G. S. Medical College and Wadia Maternity Hospital, Parel, Mumbai. He is the Founder President of the Indian Society of Prenatal Diagnosis and Therapy since 1989, and the Honorary Medical Director of the Family Planning Association of India.

$\mathrm{He}$ is the Chairman of Tata Memorial Hospital Ethics Committee, Medical Advisory Committee Emcure Pharmaceuticals, Pune, and Reliance Life Sciences Ethics Committee.

He was the President of the Federation of Obstetric \& Gynaecological Societies of India, 1996, the Indian Council Medical Research Working Group on Contraception, and the Indian Ocean Regional Medical Committee of International Planned Parenthood Federation.

Dr. Soonawala is a member of the WHO Expert Panel on Female Sterilization, the Board of Directors of the World Federation of Voluntary Surgical Contraception, and Advisory Committee of the Ministry of Family Welfare, Government of India.

Dr. Soonawala has won several awards in his career. He is one of seven people in the world to be awarded the VON GRAFFENBERG MEDAL for original work in Intrauterine Contraception by the University of Kiel, West Germany, in 
1984. He was awarded a PADMASHREE by the President of India in 1991 in recognition of work in the field of Family Planning. He also received the following awards: $D R$. VED VIAS PURI MEMORIAL AWARD in December 1999 by the Family Planning Association of India in its Golden Jubilee Year; GIANTS INTERNATIONALS AWARD in September 2000 for recognition of excellence in the Medical Field; Rashtriya Samman in July 2002 by the Income Tax Department for being one of the highest taxpayers during the Assessment years 1995-96 to 1999-2000; Labhsetwar Foundation, USA, Award on 16 January 2003 for contribution to Population Control \& Family Planning; Chikitsak Gayan Jyoti Award in December 2004 by Nations Economic for Health and Educational Growth, Delhi; and Rotary International Award in 2009.

$\mathrm{He}$ is recognized for many innovations including the modified Gynecological Operative Techniques; he designed over 12 Gynecological Instruments and two Intrauterine Contraceptive Devices.

He mobilized a team of young doctors to go to rural areas to start sterilization camps, modified the technique of vaginal sterilization, and designed instruments to make the operation simple and safe. These instruments are described in gynecological textbooks and used for many other gynecological operations.

In India, he conducted and supervised large numbers of Vasectomy \& Sterilization Camps. Over 30,000 female sterilizations have been performed with very low complication rates by these teams.

He conducted Advance Training Programs for doctors in Sri Lanka, Pakistan, Iran, Iraq, Bangladesh, Nepal, Egypt, and Thailand.

He used to box; wrestle; play tennis, badminton, and football; and run for his college and state. At the All India Olympics in 1952 and All India Inter State University, he represented Bombay state in athletics. At Intercollegiate Sports, he represented his college in athletics, hockey, football, tennis, and badminton. Furthermore, he has been a devout Zoroastrian. A versatile individual with great charisma and a charming gentlemen, who has dominated the field of obstetric and gynecology in India.

We wish him all the best! 